\title{
Conversing Across Cultures: East-West Communication Styles in Work and Nonwork Contexts
}

\author{
Jeffrey Sanchez-Burks and Fiona Lee \\ University of Michigan
}

Richard Nisbett

University of Michigan

\author{
Incheol Choi \\ Seoul National University
}

Shuming Zhao

Nanjing University

\author{
Jasook Koo \\ Seoul National University
}

\begin{abstract}
Four experiments provided evidence that East-West differences in attention to indirect meaning are more pronounced in work settings compared with nonwork settings as suggested by prior research on Protestant relational ideology. Study 1 compared errors in interpreting indirect messages in work and nonwork contexts across three cultures. Studies 2 and 3 examined differences in self-reported indirectness with coworkers versus nonwork acquaintances across three cultures controlling for variation in individualism-collectivism. Study 4 examined self-reported indirectness in bicultural managers and experimentally manipulated the salience of Western versus Eastern culture. The results showed that Americans, but not East Asians, were less attentive to indirect cues in work than nonwork settings and that East-West differences in indirectness were greater in work than nonwork settings.
\end{abstract}

Imagine you are asking a colleague for feedback on your project proposal. She looks down, nervously shuffling the papers in front of her, and says, "The logic really needs tightening, and the methodology is problematic. But otherwise, you seem to have some very interesting ideas." How would you interpret this feedback? Are you likely to focus on its explicit meaning, concluding that although the proposal needs revising, it is indeed interesting and provocative? Alternatively, are you likely to read between the lines of your colleague's comments, concluding that her equivocal manner suggests that the proposal is of questionable merit and limited value?

What the colleague means by her comment, and how the author of the proposal interprets her comment, depend in part on their focus on relational concerns. Relational concerns refer to people's motivation to use and attend to communication cues that preserve face and interpersonal harmony in their everyday

Jeffrey Sanchez-Burks, Business School and Institute of Social Research, University of Michigan; Fiona Lee, Business School and Department of Psychology, University of Michigan; Incheol Choi and Jasook Koo, Department of Psychology, Seoul National University, Seoul, Korea; Richard Nisbett, Department of Psychology, University of Michigan; Shuming Zhao, School of Business, Nanjing University, Nanjing, People's Republic of China.

This research was supported by the Russell Sage Foundation. We thank Christopher Earley, Christina Gibson, Lance Sandelands, and Margaret Shih for helpful suggestions on an earlier version of this article and Nora Gatewood and Amber Siribunrit for assistance in data collection.

Correspondence concerning this article should be addressed to Jeffrey Sanchez-Burks, 701 Tappan Street, University of Michigan Business School, Ann Arbor, Michigan 48109. E-mail: jeffrysb@umich.edu interactions (Earley, 1997; Holtgraves, 1997; Ting-Toomey et al., 1991). For example, when delivering bad news, one can show relational concern by being indirect. The colleague's equivocal appraisal of the proposal as "interesting" may be an attempt to indirectly offer criticism with minimal damage to the relationship or either person's face (Brown \& Levinson, 1987; Goffman, 1967). If the author of the proposal is also attending to indirect cues, he will be able to "read between the lines" of this comment and understand that the colleague does not think highly of his proposal (Lee, 1993). In contrast, when people do not focus on relational concerns, they are less likely to use and attend to indirectness cues, and generally expect themselves and others to be more direct in the way they communicate, or "say it as it is" (Holtgraves, 1997).

Avoiding misunderstanding therefore requires communicators to have a similar focus on relational concerns. This article examines how cultural variations can affect these kinds of misunderstandings in interpersonal conversations. Our focus is informed by research on Protestant Relational Ideology (PRI; Sanchez-Burks, 2002; Sanchez-Burks, Nisbett, \& Ybarra, 2000), which refers to a deep-seated belief that relational concerns are considered inappropriate in work settings and are attended to less compared with social, nonwork settings. Drawing on research showing that PRI has strongly influenced American culture, we suggest that although Americans are less likely to attend to indirectness cues at work than nonwork settings, these trends will not be apparent in East Asian contexts leading to a greater East-West cultural divide in work settings. Thus, we propose that East-West differences in indirectness are not stable, but vary systematically across these situations. 


\section{Indirectness and Relational Focus}

Conversational indirectness has long been considered a cause of interpersonal misunderstanding. Indirectness occurs when there is a discrepancy between sentence meaning and speaker meaning (Grice, 1968). Sentence meaning refers to the literal or semantic meaning of an utterance, and speaker meaning refers to what the speaker intends to accomplish with the remark. Thus, if the speaker says "this paper is interesting," but actually intends to communicate to the speaker that the paper has questionable worth, there is indirectness. Besides referring to how a speaker conveys a message, indirectness also affects how a listener interprets the messages of others. For example, when a listener assumes that the speaker means something beyond the sentence meaning (even if no such discrepancy exists from the speaker's perspective), the listener will attend to indirectness cues to infer the speaker meaning.

In short, indirectness reflects the speaker's and the listener's intention to do more than merely transmit the literal or sentence meaning of the words exchanged (Grice, 1968). Indirectness can be communicated through nonverbal behavior, verbal indirect meaning, or vocal emotion (Ambady, Koo, Lee, \& Rosenthal, 1996; Brown \& Levinson, 1987). For example, rather than directly criticizing a colleague's proposal, one can convey criticism using relational cues such as looking down and avoiding eye contact (nonverbal cues), offering faint praise (verbal indirect meaning), or delivering the message in a critical tone of voice (verbal emotion).

Goffman (1967) argued that indirectness reflects, in particular, the motivation to save face or create a positive public image for others. There is extensive empirical evidence demonstrating that people do indeed attend more to indirect meaning during communication when they are motivated to save face for others and preserve interpersonal harmony (Brown \& Levinson, 1987; Earley, 1997; Hall, 1983; Holtgraves, 1997; Lee, 1999; Ting-Toomey et al., 1991). Although indirectness can reflect more malevolent motivations (DePaulo \& Kashy, 1998), or lead to avoidance, vagueness, equivocalness, and even deception (Lee, 1993), indirectness typically signals one's concern for another's face.

\section{Indirectness and Culture: The Role of PRI}

Indirectness has been shown to vary between cultures (for reviews, see Markus \& Kitayama, 1991; Ting-Toomey et al., 1991). Hall (1983) reported that there is more indirectness in high-context cultures where people rely on a broad array of social cues to communicate than in low-context cultures where people rely on few social cues to communicate. In a similar vein, people from collectivist cultures (such as Koreans) have been shown to be more indirect than people from individualistic cultures (such as Americans) (Ambady et al., 1996; Holtgraves, 1997). This difference presumably stems from collectivists' tendencies to attend to relational concerns more than individualists (Ting-Toomey et al., 1991).

Departing from this focus on cross-cultural mean differences, recent research on PRI suggests that the magnitude of East-West differences in relational attentiveness and indirectness varies across work and social settings. PRI describes a cultural norm in which relational concerns are considered less appropriate in work than nonwork settings (Sanchez-Burks, 2002). This ideology can be traced to the beliefs and social practices of the American
Calvinist Protestants during the 17th and 18th centuries (Weber, 1947). The Calvinist's theology and social practices focus on the different meanings of work and leisure (Lenski, 1963), and particularly stressed the importance of limiting social-emotional and interpersonal concerns in the domain of work. Although these guidelines suggest that individuals ought to maintain an unsentimental impersonality at work, this relational asceticism did not apply outside of work (Daniels, 1995). In short, PRI focuses on the differing levels of relational attentiveness between work and nonwork settings. ${ }^{1}$

Over time, PRI was secularized and incorporated in the contemporary ethos of American culture, such that one is typically expected to be more impersonal and emotionally detached at work (Weber, 1947). There is evidence, for example, that PRI is stronger among European Americans compared with Latin Americans and Mexican Americans and among Americans raised with Calvinist Protestantism (e.g., Presbyterian, Methodist) compared with those raised in non-Protestant sects (e.g., Catholics and Unitarians) (Sanchez-Burks, 2002; Sanchez-Burks et al., 2000). These studies suggest that individuals with greater exposure to PRI (e.g., Americans vs. Latins, or Presbyterians vs. non-Protestants) are less attentive to relational cues in work than nonwork settings.

In contrast, research in cultures not associated with Calvinism (and thus PRI) shows that individuals exhibit an equally strong emphasis on relational concerns in both work and nonwork settings (for an excellent review, see Earley, 1997). East Asian cultural syndromes such as amae in Japan or guanxi in China share a common emphasis on relational concerns across all domains from the dinner table to the office (Bond, 1986; Farh, Tsui, Xin, \& Cheng, 1998). Cross-cultural scholars have even suggested that, in East Asian organizations, attention to relational cues is heightened rather than attenuated at work settings because of greater formality and power dynamics (Triandis, Dunnette, \& Hough, 1994). Despite different reasons specific to each society for this maintained relational focus, they contrast similarly with American culture in not diminishing this focus within the context of work.

\section{Present Research}

Taken together, prior research demonstrates that individuals socialized within cultural contexts steeped in PRI leads to less attentiveness to relational cues in work settings compared with nonwork or social settings. Accordingly, we predict that for Americans, indirectness would be less common in work compared with nonwork settings, but this difference would be less apparent in China or Korea (Hypothesis 1).

Given that PRI suggests that Americans, but not East Asians, would be less attentive to relational cues in the workplace, we further predict that East-West difference in indirectness is greater in work settings compared with nonwork settings (Hypothesis 2). This hypothesis suggests that Americans are particularly less attuned to indirect cues than East Asians in work settings. In nonwork settings, we predict that Americans and East Asians will be similarly attentive to indirectness. Hypothesis 2 contradicts the

\footnotetext{
${ }^{1}$ PRI is distinct from Protestant Work Ethic. Protestant Work Ethic advocates the value of work in its own right, self-reliance, and limiting personal indulgence (Furnham, 1990).
} 
notion that cultural values are more likely to converge in the workplace. As a result of increased market globalization, managers around the world are often educated within American business schools and have extensive experience in multiple cultural contexts. These trends are thought to reduce cultural variation in work settings by creating a "universal" work style. In contrast to this argument, we predict that cross-cultural differences in indirectness will be amplified rather than diminished in the workplace.

To test these hypotheses, we conducted four cross-cultural experiments comparing indirectness across work and nonwork contexts within and between cultures. In Study 1, American, Korean, and Chinese participants read an indirect feedback message framed within either a work or nonwork context, and made interpretations about the intended meaning of the message. Study 2 compared responses from American, Chinese, and Korean participants on a cross-culturally validated survey measure of conversational indirectness. Participants answered the items with respect to a coworker or a nonwork acquaintance. Study 3 sought to replicate Study 2 while controlling for differences in collectivism and individualism. Study 4 used an alternative method of cultural comparison by experimentally manipulating the salience of American culture and Eastern culture.

\section{Study 1}

Study 1 examined how Americans and East Asians interpret indirect messages in work and nonwork settings. If people attend less to indirect relational cues, it should follow that they will more likely misinterpret the meaning of an indirect message. Thus, we expect Americans to make more errors in interpreting indirect messages at work than nonwork settings, but we do not expect East Asians to show differences in errors between work and nonwork settings (Hypothesis 1). We further expect East-West differences in errors to be more evident in work settings than nonwork settings (Hypothesis 2).

\section{Method}

Participants. Participants were 55 European Americans (37 men, 18 women; mean age $=28.92$ years), 59 Chinese ( 41 men, 18 women; mean age $=27.44$ years), and 47 South Koreans ( 44 men, 3 women; mean age $=35.23$ years). The American participants were drawn from two large business schools, one from the Midwestern United States and one on the West Coast of the United States. Korean participants were from a business school in Seoul, Korea. The Chinese participants were drawn from a business school in Nanjing, China. Participants were recruited through Master of Business Administration (MBA) courses. Participants had a minimum of 4 years working experience, which occurred in their respective countries.

Materials and procedure. All participants were tested in their native language. Participants were randomly assigned to either a work or nonwork condition. In the work condition, participants were asked to imagine that they were working for a large company and were in charge of compiling and organizing information from employee performance evaluations. Participants were told that the original evaluation form for one employee was lost. All that remained was the transcript of the meeting between the reviewer and the reviewee.

The transcript was taken from a previous study in which American participants were given a partner's poor performance ratings, and asked to write a note to the partner about the content of the evaluation (Lee, 1993).
In Lee's (1993) study, the rating form had 14 performance dimensions such as "organization skills" and "communication skills," each rated on a 9-point Likert scale $(1=$ very poor, $5=$ average, $9=$ very good $)$. All the scores were extremely low, and the average across all items was 3.14. In Lee's (1993) study, the notes that participants wrote communicating the content of these ratings were coded for indirectness. We identified a note that scored in the 95th percentile of indirectness from Lee's (1993) study, and used it as the stimulus in the present study. Specifically, the note said,

This is your interim evaluation summary: Overall the evaluation indicates that your strengths are in communication skills, anticipating events and creativity. The other areas are not as strong as these-some are poor, but frankly it's difficult to evaluate those areas. Good job!

Bilingual Chinese and Koreans translated the note, and the translated note was back-translated into English by a separate set of Chinese and Korean bilinguals. No conceptual discrepancies were found between the original and back-translated notes. Participants in the present study received this note in their native language, along with a blank copy of the original evaluation form. Participants were told that their task was to reproduce the original evaluation ratings as best they could from the note. The task is essentially Lee's (1993) study in reverse. Rather than giving people actual ratings and asking them to convey the results in a written message as Lee did, in the present study we gave participants a written message and asked them to estimate the actual ratings.

In the nonwork condition, participants were told to imagine overhearing two friends talking about the results of a personality test. The friends agreed to score each other's test and then tell each other how they did on the test. Participants were given a transcript of what one friend told another friend, and then asked to reproduce the exact ratings of the personality test. The transcript and the rating form were identical to those used in the work condition. Pretesting of the materials in each culture ( $n=15$ per culture) showed that $100 \%$ of the participants in the work condition interpreted the feedback as work related, and $100 \%$ of the participants in the nonwork condition interpreted the feedback as unrelated to work. This established that the instructions for the manipulation were clear and easy to follow in each culture.

Participant's ratings for the 14 items were averaged to create an overall estimation score. The reliability (Cronbach's alpha) across the14 items was .75. Given that the specific message used in the present study was written to convey a poor evaluation (average score of 3.14 out of 9.00), participants who were less attentive to indirectness should have higher estimates of the ratings.

\section{Results}

A 2 (context: work vs. nonwork) $\times 3$ (culture: American, Chinese, Korean) analysis of variance (ANOVA) was conducted using estimation scores as the dependent variable. There were no significant main effects for context or culture $(p s>.70){ }^{2}$ There was a nonsignificant trend for the Context $\times$ Culture interaction, $F(2,156)=1.95, p=.14$.

Hypothesis 1 predicted that Americans would make more errors of interpretation (would be less sensitive to indirect cues) in work settings compared with nonwork settings, whereas East Asians would not show differences between work and nonwork settings. As predicted, planned contrasts indicated that Americans overestimated the actual evaluation ratings more in the work setting $(M=6.24)$ compared with the nonwork setting $(M=5.86)$,

\footnotetext{
${ }^{2}$ All $p$ values reported are based on two-tailed tests.
} 
$t(156)=2.33, p=.03$. This difference was not significant for Chinese $(M=6.44$ work vs. $M=6.38$ nonwork) or Koreans ( $M=6.0$ work vs. $M=6.26$ nonwork), both $t$ s $<1$. Overall, Hypothesis 1 was supported.

Hypothesis 2 predicted that East-West differences in errors would be stronger in work than nonwork settings. However, contrasts that examined differences between Americans and East Asians (Chinese or Koreans) were not significant in both work and nonwork settings (all $p$ s $>.05$ ). Thus, Hypothesis 2 was not supported. There were no differences in errors between Chinese and Koreans in both work and nonwork settings (all $p s>.05$ ).

Combining Hypotheses 1 and 2, Americans in work settings are predicted to have more errors (or less indirectness) than all other conditions combined (American/nonwork, Chinese/work, Chinese/ nonwork, Korean/work, and Korean/nonwork conditions). The contrast to test this prediction was not significant, $p>.05$.

\section{Discussion}

In Study 1, we examined errors in interpreting an indirect feedback message. Being direct-that is, inferring "speaker meaning" directly from "sentence meaning"-in the message we provided to participants results in more errors of interpretation. Consistent with our predictions, the results showed that Americans made more errors in interpreting indirect messages in work than nonwork settings. This difference did not appear among Chinese or Korean participants.

Although the within-cultural differences emerged as predicted, we found no reliable cross-cultural differences in either the work or nonwork settings. However, the present methodology has features that limit the ability to make strong inferences about crosscultural differences. First, the indirect message that participants were asked to interpret was originally generated by an American, which may bias estimations in favor of the American sample. For example, the message contained American idioms and colloquialisms (e.g., "frankly," "good job"), and these terms may be somewhat distorted through the translation process. Indeed, the Chinese and Korean samples made slightly more errors (though not significantly) than the Americans. It is not clear whether this is due to actual cross-cultural differences in indirectness, or whether it is because an American originally wrote the message.

Also, Study 1 focused on indirectness in interpretation, that is, whether the recipient of the message used indirectness cues to interpret speaker meaning. However, this study did not examine the use of indirectness cues by the speaker. Study 2 addresses these issues by using a cross-culturally validated survey that measures indirectness for both message interpretation and message conveyance.

\section{Study 2}

Study 2 consisted of a 2 (context: nonwork or work) $\times 3$ (culture: American, Chinese, or Korean) between-subjects design. American, Korean, and Chinese participants completed Holtgraves's (1997) self-report measure of indirectness while thinking of a work or nonwork related relationship. We hypothesized that Americans would report lower levels of indirectness in the work survey than the nonwork survey, whereas East Asians (Chinese or Koreans) would show no differences between the work and non- work surveys (Hypothesis 1). We also hypothesized that differences in indirectness between Americans and East Asians would be greater in the work survey than the nonwork survey (Hypothesis 2).

\section{Method}

Participants. Thirty-five European Americans (29 men, 6 women; mean age $=30.11$ years), 58 South Koreans (50 men, 8 women; mean age $=31.92$ years), and 59 Chinese (36 men, 23 women; mean age $=27.43$ years) MBA students participated in the study. As in Study 1 , the American participants in this study were drawn from a business school in the Midwest and a business school on the West Coast of the United States. Korean participants were drawn from two sources: half were MBA students in a business school in Seoul, Korea, and half were enrolled in a global MBA program where they took some courses in the United States. We compared the two Korean samples on indirectness and found no statistical differences between them. Thus, the two samples were combined in all the analyses. The Chinese participants were drawn from a business school in Nanjing, China. Participants were recruited through MBA courses and e-mail groups, and had a minimum of 4 years working experience, all of which occurred in their respective countries.

Materials and procedure. Study 2 used a modified version of Holtgraves's (1997) indirectness scale to measure participants' self-reported levels of conversational indirectness. This scale included items that measure whether indirectness is used to interpret messages (such as "I try to consider all interpretations of others' remarks before deciding what they really meant"), as well as items used to measure whether indirectness is used to convey messages (such as "Most of what I say can be taken at face value, and there is no need to look for deeper meaning").

Two versions of Holtgraves's (1997) indirectness survey were createdthe work version and the nonwork version. In the work version, participants were asked to think of "a specific person with whom they interact only at work." In the nonwork version, participants were asked to think of "a specific person with whom they interact only outside of work." Participants were asked to respond to all the survey items with this target person in mind. The original scale items were modified by inserting the phrase "When interacting with X at work (or outside work) . .." before each item, where "X" refers to the target person. A sample item is "When interacting with $\mathrm{X}$ at work, I try to consider all interpretations of X's remarks before deciding what he or she really meant." All items were rated on a 7-point scale $(1=$ agree completely, $7=$ disagree completely $)$

Bilingual native speakers of Korean and Chinese translated the survey from English into Korean and Chinese versions. Separate bilinguals performed back-translations into English to ensure conceptual equivalence. No conceptual discrepancies were found between the original and backtranslated versions. Pretesting of the measures in each culture $(n=20$ per culture) found that $100 \%$ of participants in the work condition thought of a person from work, whereas $100 \%$ of participants in the nonwork condition thought of a person from outside of work.

All participants were randomly given the work or nonwork survey, and all participants completed the survey in their native language. After reverse scoring appropriate items, ratings for each item were averaged to create the indirectness index with higher scores indicating higher levels of indirectness (overall Cronbach's $\alpha=.87$, Americans $\alpha=.84$, Koreans $\alpha=.91$, Chinese, $\alpha=.83$ ). Holtgraves's (1997) scale measures indirectness in message conveyance and message interpretation; however, as in previous studies, these two components of the scale were highly correlated $(r=.81$, $p<.01)$. Thus, rather than reporting the results of message conveyance and message interpretation separately, a single indirectness index was used.

\section{Results}

A Culture $\times$ Context ANOVA was performed on the indirectness index. The main effect of culture was not significant $(p>$ 
.20) nor was the main effect of context $(p>.60)$, but the Culture $\times$ Context interaction was significant, $F(2,146)=4.84$, $p=.009$. As shown in Figure 1, Americans were significantly less indirect in work compared with nonwork settings, $t(146)=2.09$, $p=.039$. However, the same trend was not apparent for Koreans and Chinese, supporting Hypothesis 1. Surprisingly, we found that East Asians were more indirect in work than nonwork settingsthe effect was significant for Koreans, $t(146)=2.16, p=.032$, but not significant for Chinese, $t(146)=1.52, p=.13$.

Within work settings, Americans were significantly less indirect than Koreans, $t(146)=3.25, p=.001$, and Chinese, $t(146)=2.90, p=.004$, whereas within nonwork settings there were no East-West differences (both $p s>.60$ ). These results support Hypothesis 2. Overall, there were no differences between the Chinese and Korean samples (all comparisons between Chinese and Koreans yielded $p s>.65$ ). The contrast examining the combined predictions of Hypotheses 1 and 2 (i.e., Americans/work have lower indirectness than all other conditions combined) was significant, $t(146)=2.73, p=.007$.

\section{Discussion}

The results of Study 2 showed that, as predicted, indirectness was lower in work than nonwork relationships for Americans, but this pattern was not evident for East Asians. The results also showed that, as predicted, East-West cultural differences in indirectness were larger in work than nonwork contexts.

Although we did not anticipate any differences in indirectness between work and nonwork contexts for Easterners, we found that Koreans, and to a lesser extent, Chinese, were more indirect in work than nonwork settings. Together, Studies 1 and 2 show that Americans and East Asians relate to each other in different ways in work versus nonwork settings. We suggest that our pattern of findings can be explained by Americans' exposure to PRI-beliefs that relational concerns should be set aside at work. However, our findings thus far might also be explained by differences in levels

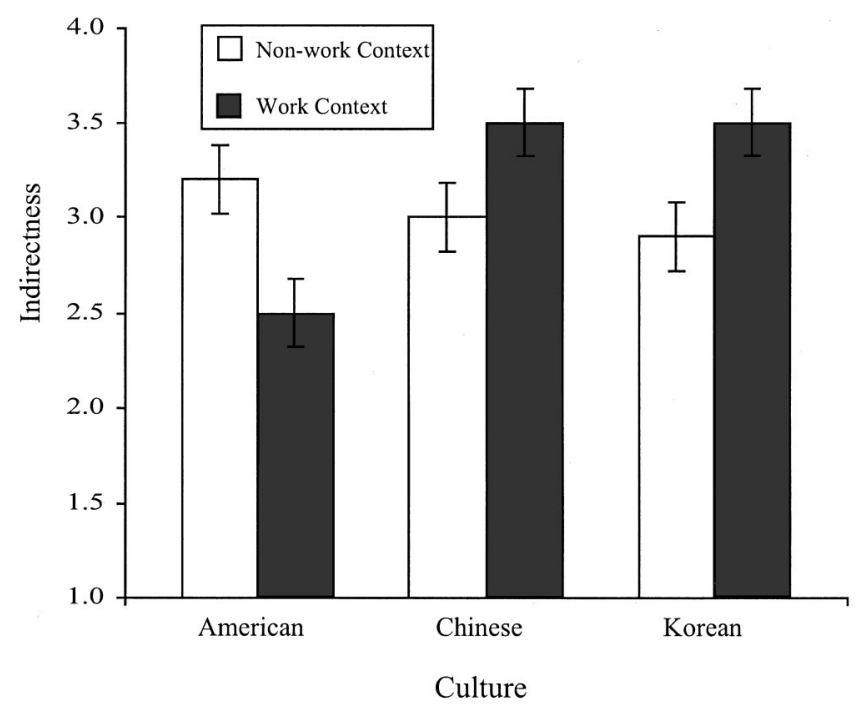

Figure 1. Indirectness as a function of context and participant's culture (Study 2). Error bars represent one between-subjects standard error. of collectivism or individualism (INDCOL). INDCOL is one of the most widely used dimensions to understand cross-cultural differences and it has been linked to attention to relational cues and indirectness. For example, there is evidence that collectivists are more likely than individualists to use communication strategies such as indirectness to avoid social discord and threats to face (Holtgraves, 1997).

Although INDCOL does not provide any direct predictions of how indirectness may differ between work and nonwork settings, there is some evidence showing that individual levels of INDCOL vary on the basis of exposure to different external stimuli (e.g., Trafimow, Triandis, \& Goto, 1991). It is possible that the American workplace, in contrast to those in East Asia, is more likely to deemphasize collectivist values such as teamwork and interpersonal harmony. This could lead Americans to become less collectivistic in work settings, which in turn leads to less indirectness at work. To rule out this alternative explanation, Study 3 was conducted.

\section{Study 3}

Study 3 examined whether the predicted interaction between culture and context can be explained by differences in levels of individualism or collectivism. Study 3 used a design similar to Study 2 but also included measures of individualism and collectivism. In addition, the East Asian sample in Study 3 included individuals born and raised in Korea, China, Singapore, Taiwan, or Japan. As in the previous studies, we predicted that Americans but not the East Asians would be less indirect in work than nonwork settings (Hypothesis 1), and that the East-West cultural difference would be greater in work than nonwork settings (Hypothesis 2). On the basis of previous studies on INDCOL and communication styles, we anticipated that collectivism would account for main effect cultural differences in indirectness. Thus, we predicted (a) that East Asians would report higher levels of collectivism than Americans, (b) that higher levels of collectivism would be associated with higher levels of indirectness, and (c) that East-West differences in indirectness would not be apparent after controlling for collectivism. However, theoretical and empirical accounts of INDCOL do not suggest any specific differences between work and nonwork context, and thus we do not expect INDCOL to account for the predicted interaction between culture and work/ nonwork settings. In short, we predict that even when controlling for differences in levels of collectivism, we will find evidence for Hypotheses 1 and 2.

\section{Method}

Participants. Participants were 82 European American (50 men, 32 women; mean age $=21.01$ years) and 137 East Asian (63 men, 74 women; mean age $=21.12$ years) undergraduate business students enrolled in a large university on the West Coast of the United States. Participants were given extra course credit. Participants were considered European American if they were born in the United States and used English as their first language. Participants were considered East Asian if (a) they held citizenship and were born in an East Asian country (65\% Korea, 31\% China, 4\% Singapore, Taiwan, or Japan), (b) their first language was Mandarin, Cantonese, or Korean, and (c) they had lived in the United States for less than 5 years (none of the East Asian participants considered themselves Asian American). 
Materials and procedure. All participants completed a survey in English. Participants first filled out a 32-item INDCOL scale (Singelis, Triandis, Bhawuk, \& Gelfand, 1995). After reverse scoring negatively worded items, items within each subscale were averaged to create the 16-item collectivism index (overall Cronbach's $\alpha=.71$; Americans $\alpha=$ .75 , East Asians $\alpha=.70$ ) and the 16-item individualism index (overall Cronbach's $\alpha=.74$, Americans $\alpha=.74$, East Asians $\alpha=.74$ ), respectively. The collectivism and individualism subscales were not significantly correlated $(r=-.07, p>.05)$.

As in Study 2, participants also filled out the modified Holtgraves's (1997) indirectness scale. Participants were randomly given the work or nonwork version of the survey. After reverse scoring negatively worded items, the indirectness items were averaged to create the indirectness index with higher scores indicating higher levels of indirectness (overall Cronbach's $\alpha=.89$, Americans $\alpha=.87$, East Asians $\alpha=.90$ ).

\section{Results}

The indirectness index and collectivism measure were correlated positively $(r=.13, p=.05)$, showing that higher levels of collectivism were associated with higher levels of indirectness. ${ }^{3}$ We first conducted a 2 (culture) $\times 2$ (context) ANOVA on the collectivism measure, which showed that East Asians $(M=5.20)$ were more collectivistic than European Americans $(M=4.83)$, $F(1,215)=18.60, p<.001$. Neither the context main effect nor the Culture $\times$ Context interaction reached significance (all $\left.F_{\text {s }}<1\right)$. Thus, levels of collectivism did not appear to vary across contexts within or across cultures. Analyses on the individualism measure revealed that it was not reliably correlated with the indirectness index $(p>.05)$, and it did not differ significantly across cultures or contexts within or across cultures (all $p$ s $>$.10). Thus, individualism was not included in subsequent analyses.

Next we conducted a 2 (culture) $\times 2$ (context) ANOVA on the indirectness index. The context main effect was not significant, $F(1,214)=2.23, p=.14$. There was a main effect of culture, $F(1,214)=5.16, p<.03$, indicating that East Asians were more indirect compared with European Americans. We found a significant Culture $\times$ Context interaction, $F(1$, $214)=5.17, p<.03$, replicating the pattern found in Study 2 . Consistent with Hypothesis 1, Americans were significantly less indirect in work settings $(M=2.94)$ compared with nonwork settings $(M=3.72), t(214)=2.70, p>.008$, but the same difference was not observed among East Asians $(M=3.74$ vs. $M=3.61), t(214)=0.63, p>.53$. Consistent with Hypothesis 2, Americans were significantly less indirect than East Asians at work, $t(214)=3.35, p<.01$, but Americans and East Asians did not differ in indirectness in nonwork settings $t(214)=0.30, p>.76$.

Together, Hypotheses 1 and 2 suggest lower levels of indirectness for Americans in the work condition compared with the three other conditions. The contrast of this prediction shows that indeed, indirectness was lower in the American/work condition compared with the American/nonwork, Asian/work, and Asian/nonwork conditions combined, $t(214)=3.57, p<$ .001 .

Of most importance, we conducted a Culture $\times$ Context analysis of covariance (ANCOVA) on indirectness with collectivism as the covariate. The ANCOVA revealed that the main effect of culture in indirectness was no longer statistically significant after control- ling for differences in collectivism $(p>.10)$. This suggests that differences in collectivism accounted for the main effect of cultural differences in indirectness. The ANCOVA revealed a significant Culture $\times$ Context interaction even when controlling for collectivism, $F(1,213)=6.83, p<.02$. As shown in Figure 2, the interaction was in the predicted direction. Moreover, the interaction effect size remained relatively unchanged when collectivism was added as a covariate ( $d=3.13$ vs. $d=3.06$ ), further suggesting that collectivism offered little explanatory power for the predicted Culture $\times$ Context interaction.

\section{Discussion}

Study 3 added to Studies 1 and 2 in several ways. First and foremost, Study 3 examined whether individualism or collectivism could explain the predicted interaction between culture and work/ nonwork contexts. Although we found that overall cross-cultural differences in indirectness could be accounted for by East-West differences in collectivism, it did not account for how Americans and East Asians communicated differently in work versus nonwork settings. Not only were there no differences in collectivism between work and nonwork conditions, we found support for our hypotheses even when we controlled for differences in collectivism. The results also revealed that levels of individualism did not vary across European Americans and East Asians, nor was it related to levels of indirectness. In short, although general EastWest differences in indirectness could be understood within the collectivism framework, collectivism or individualism could not explain context-specific differences in indirectness.

Second, Study 3 used younger participants (undergraduates rather than MBA students). This is significant as this sample is considerably less likely to have prior working experience, suggesting the possibility that culturally grounded relational styles for the workplace may be developed relatively early in life, before one enters the work force.

So far, Studies 1, 2, and 3 relied on cross-national comparisons between American, Korean, and Chinese students. Although we found differences consistent with our predictions using these comparisons, these comparisons do have some limitations. In particular, there are many dimensions along which cross-national samples can differ besides culture. For example, a plausible alternate explanation for our findings is that East Asian work contexts are more likely than American work contexts to include family members or close friends (e.g., Hui \& Luk, 1997). Thus, when responding to our work-related indirectness survey, East Asian participants may have thought of a family member who also happened to be a coworker. Given that the target is someone the participant interacts with in multiple and overlapping domains (i.e., work and family), the relationship may have added significance, leading to more attentiveness to indirectness. There are other ways the East-West samples may differ. For example, the Eastern and Western samples in Studies 1-3 may be used in different types and sizes of firms, the types of nonwork relationships they have, and exposure to

\footnotetext{
${ }^{3}$ Preliminary analyses revealed no reliable differences between the different East Asian groups in indirectness, individualism, or collectivism Because of small sample sizes in many of these groups and to increase overall power, data from these groups were combined for subsequent analyses.
} 


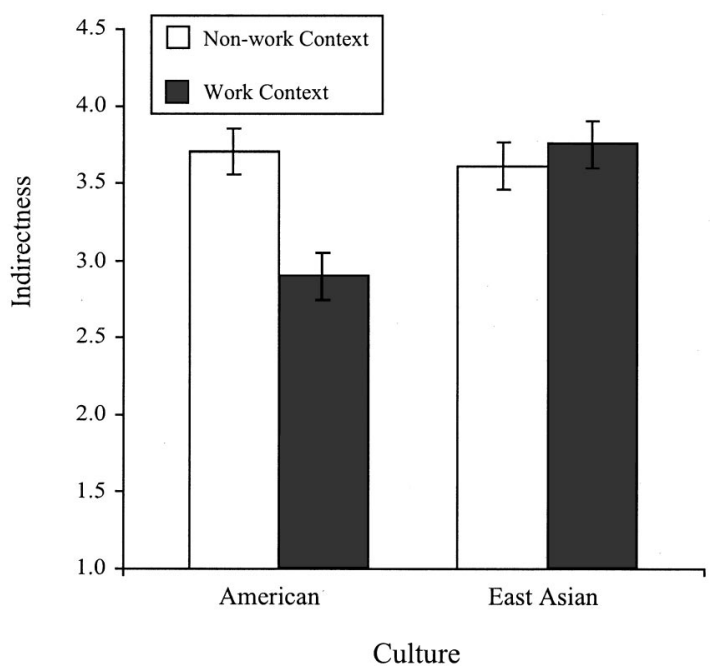

Figure 2. Indirectness as a function of context and participant's culture controlling for differences in individualism-collectivism (Study 3). Error bars represent one between-subjects standard error.

other cultures besides their own. To address these issues, we conducted Study 4 in which we manipulated the salience of Eastern or Western culture among bicultural employees in multinational firms.

\section{Study 4}

Study 4 examined indirectness with biculturals, specifically individuals experienced with both East Asian and American cultures (LaFromboise, Coleman, \& Gerton, 1993; Phinney \& Devich-Navarro, 1997). According to recent conceptualizations of culture, individuals can have access to multiple cultural identities that can be activated by cultural cues in the environment (Hong, Morris, Chiu, \& Benet-Martínez, 2000). There is evidence, for example, that biculturals-individuals who are experienced with more than one culture - are able to show patterns of behavior associated with either culture when exposed to "cultural cues," or characteristic symbols, language, music, or dress representing particular cultures. For example, after Chinese American biculturals viewed American pictures (e.g., Mickey Mouse), they behaved in more characteristically Western ways (e.g., making more internal attributions, or rating the self as more independent). Alternatively, when Chinese American biculturals viewed Chinese pictures (e.g., the Great Wall), they behaved in more characteristically Eastern ways (Hong, Chiu, \& Kung, 1997).

Using this approach, Study 4 manipulated the salience of Western or Eastern culture among bicultural participants and examined their self-reported levels of indirectness. The cultural salience manipulation was conducted by exposing East-West biculturals to either Western cues (English language survey) or Eastern cues (Eastern language survey). We predict that participants who received the English survey would behave in characteristically Western ways-exhibiting less indirectness in work than nonwork relationships. In contrast, participants who received the Eastern language survey would behave in characteristically Eastern ways-exhibiting equivalent levels of indirectness in work and nonwork relationships (Hypothesis 1). Further, we predict that differences in indirectness between the English language survey and Eastern language survey would be greater in work than nonwork settings (Hypothesis 2). By experimentally manipulating culture using cultural cues-in this case, the language of the survey-we can rule out important artifacts that may have been present in the cross-national designs of the previous studies.

\section{Method}

Participants. Participants were 151 (103 female, 48 male; mean age $=31.22$ years) Thai-English bilinguals recruited from two large multinational corporations in Thailand. Both corporations were Fortune 500 companies headquartered in the United States. One company was a bank, and the other a food manufacturing company. All participants indicated that they were equally fluent in both Thai and English languages. Participation was voluntary.

Materials and procedure. As in Study 2, we first translated Holtgraves's (1997) indirectness survey into Thai, and then checked the adequacy of the translation with back-translation. One version of the survey focused on work relationships, and one version focused on nonwork relationships. Overall, four versions of the survey were created: English/ work, English/nonwork, Thai/work, and Thai/nonwork.

Surveys written in English or Thai were distributed to 225 employees in the two companies. Participants were randomly given one of the four versions of the indirectness survey. A cover letter describing the general topic of the study was included with the survey, as well as a return envelope. Of the 225 surveys distributed, 151 were returned, yielding a total response rate of $67 \% .^{4}$

\section{Results}

Indirectness scores were calculated using the same method as in Studies 1-3. A 2 (cultural cues: English or Thai language surveys) $\times 2$ (context: work or nonwork context) ANOVA was conducted on the mean indirectness scores. The main effect for context was not significant $(p>.05)$. Participants who received the Thai survey were marginally more indirect $(M=3.57)$ than participants who received the English survey $(M=3.19), F(1$, $147)=2.77, p=.10$. The predicted Culture $\times$ Context interaction was significant, $F(1,147)=3.97, p=.05$. As shown in Figure 3, participants who received the English survey reported less indirectness at work than outside work, $t(147)=2.36, p=.01$, whereas participants who received the Thai survey reported equal levels of indirectness in both contexts, $t(147)=0.11, p=.46$, supporting Hypothesis 1. In addition, the differences between the cultural cues conditions were stronger in work than nonwork settings - indirectness was lower in the English/work survey than the Thai/work survey, $t(1,147)=3.06, p=.001$, but there were no differences between the English and Thai nonwork surveys, $t(1,147)=0.76, p=.22$. These findings support Hypothesis 2 .

\footnotetext{
${ }^{4}$ Response rates were slightly different for Thai and English surveys (83\% and 54\%, respectively). Even though all participants initially approached for the study reported being equally fluent in English and Thai, it may be the case that some respondents might have exaggerated their fluency with English in the initial recruitment stage of the study because they worked in an American corporation. The experimental design of the study guarded against some issues of response bias, however, by focusing primarily on differences within each version (i.e., Thai or English) of the survey.
} 


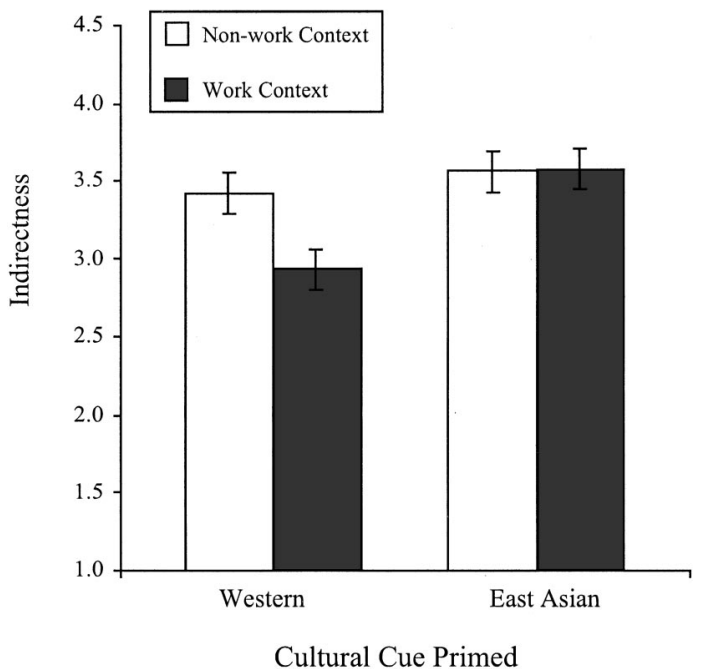

Figure 3. Indirectness as a function of context and cultural prime (Study 4). Error bars represent one between-subjects standard error.

Following our analytic strategy in Studies 1-3, we conducted a weighted contrast to examine whether indirectness in the English/ work condition was lower compared with the other conditions combined. This contrast was significant, $t(147)=2.83, p=.003$.

\section{Discussion}

By experimentally manipulating the salience of Eastern and Western culture, Study 4 provides further support for our hypotheses and rules out confounds in cross-national comparisons. In Study 4, we found that participants randomly assigned to Western cultural cues (English language survey) behaved like Americans (being less indirect at work than nonwork settings), whereas participants randomly assigned to Eastern cultural cues (Chinese language survey) behaved like East Asians (being equally indirect at work and nonwork settings). One concern, however, is that the English language prime cued Western culture more broadly rather than American culture specifically. Although it is plausible that given the participant's daily experience working for an Americanbased corporation, the English language indeed cued an "American" cultural frame more specifically, this remains an untested assumption.

Findings from cultural priming technique used with bicultural individuals lends support to the idea that multiple cultural schemas can be mentally represented and integrated by individuals, and which cultural schema is activated depends on the external situation. Rather than being a monolithic and stable entity, culture is dynamic, flexible, and responsive to situational cues (Hong et al., 1997). Our findings show that people's attention to relational cues-when and whether indirectness is used in interpersonal communication-is also dynamic, flexible, and responsive to situational cues. As demonstrated in this study, the study of culture does not inherently require cross-national comparisons; patterns of individual variation provide important insights about cultural dynamics while controlling for broad-based societal differences.

\section{General Conclusions}

In this article, we examined individual, contextual, and cultural variation in indirectness. Our hypothesized patterns were found using different methodologies across multiple cultural groups (United States, China, Korea, Thailand, Japan, Singapore, and Taiwan). Study 1 measured participants' accuracy in interpreting indirect feedback, whereas Studies 2-4 used self-report measures of indirectness in both message interpretation and message conveyance. Studies 1 and 2 compared the responses of cross-national samples, Study 3 compared different ethnic groups within the United States, and Study 4 experimentally manipulated culture among biculturals. Studies 1 and 2 used MBA students, Study 3 used undergraduates, and Study 4 used employees in large corporations. Different East Asian groups were examined across the four studies-Studies 1-3 examined Chinese and Koreans and Study 4 examined Thais.

These results are consistent with prior research on PRI, showing that Americans exhibit a lower level of attention to relational cues in work settings compared with nonwork settings. We further demonstrated that East-West differences in indirectness are relatively dynamic and sensitive to situational contexts; specifically, East-West differences in indirectness are pronounced within work settings but not apparent in nonwork, social settings. Moreover, our results show that this pattern cannot be attributed to differences in individualism or collectivism (Study 3) or other factors confounded with cross-national comparisons such as differences in work and nonwork networks (Study 4).

Although this article focused on comparisons between American and Asian communication styles, the theoretical framework suggested by PRI research implies that contrasting Americans with people from other cultures would yield similar patterns. Despite enormous differences in the nature of social relations across societies as diverse as Mexico, Japan, and India, the United States may differ from each of them in exposure to PRI, and thus reduce social emotionality in work settings. For example, strong traditions of social emotionality in work relations have been documented in Mexico (Triandis, Marin, Lisansky, \& Betancourt, 1984; SanchezBurks et al., 2000), India (Kool \& Saksena, 1988), and many Middle Eastern cultures (Hui \& Luk, 1997). Similar to the East Asians in the present studies, we would expect that Americans have more pronounced differences in indirectness within work settings compared with nonwork settings vis-à-vis individuals from one of these cultures.

\section{Implications for Bridging Cultural Divides}

Our research has several implications for cross-cultural working relationships. Our results consistently demonstrated that EastWest differences in indirectness are more pronounced in work than nonwork contexts. This suggests that a diverse workplace with individuals from different cultures and ethnic groups is a particularly fertile ground for miscommunication and misunderstandings. This finding challenges the idea that globalization minimizes cultural differences in the context of work, and underscores the challenge of fostering successful cross-cultural communication in organizations.

Our findings also suggest possible ways to bridge this cultural divide in organizations. Our results demonstrate that, 
rather than being generally inattentive to relational cues, Americans can be just as attentive to relational clues as East Asians given the right conditions. As our results reveal, Americans are just as indirect as East Asians in social situations. Thus, one possible strategy for reducing cultural miscommunications at work is to activate Americans' nonwork relational schemas in the workplace. This could be accomplished through a variety of methods. For instance, one could create informal environments where employees from different cultures could frequently interact socially with each other. Given that East-West differences in indirectness are minimal in nonwork settings, such an intervention can create effective "baseline" communication norms, processes, and expectations that employees can use at work. Similarly, miscommunication can be reduced if more cross-cultural work discussions are conducted in social contexts outside the workplace. Back to our initial example, if the author of the paper and the colleague giving the feedback are from different cultures, the chance of miscommunication may be lessened if they discussed the paper in a nonwork setting. Overall, it appears that multiple opportunities for "extracurricular" activities and informal interactions at work can play an important role in reducing cross-cultural misunderstandings in communication.

Relatedly, although our research shows that people behave differently in work and nonwork settings, more research is needed to examine the specific psychological dimensions underlying how work and nonwork settings differ. Just as people have different schemas-mental models for how one should think, feel, and behave-for different settings such as going to a restaurant, being on a date, going to class, and so on (Baldwin, 1992), our findings suggest people also have schemas for work and nonwork settings. Specifically, we found that, at least for Americans, there are different ways to communicate with others at work and outside of work. When Americans focus on workplace interactions (by engaging in a work-related task, or thinking about a workplace colleague), workplace schemas are activated, leading them to exhibit less indirectness. However, a limitation of our studies is that it is not clear what dimensions of the workplace setting activate this schema. For example, if performing a work-related task (such as assembling performance evaluations in Study 1) would elicit a work-based behavioral schema, then it may be possible to activate Americans' nonwork relational schemas in the workplace simply by giving them tasks that are not prototypically work related (e.g., "extracurricular" activities at work). Alternatively, if being with colleagues would activate a work schema, then simply asking coworkers to engage in nonwork related activities might not be sufficient to activate nonwork schemas.

In conclusion, Weber (1904/1930) noted in his famous treatise that Protestant ideologies contributed to economic prosperity and effective business organizations in America and Western Europe. Although PRI in particular may be essential to the success of Western business organizations, our findings suggest that it may serve as a barrier to a global and cross-cultural business environment by exacerbating cross-cultural differences in the workplace. Insights from the present research can bridge these barriers by illuminating the conditions that facilitate or hinder effective communication across cultures.

\section{References}

Ambady, N., Koo, J., Lee, F., \& Rosenthal, R. (1996). More than words: Linguistic and nonlinguistic politeness in two cultures. Journal of Personality and Social Psychology, 70, 996-1011.

Baldwin, M. W. (1992). Relational schemas and the processing of social information. Psychological Bulletin, 112, 461-484.

Bond, M. (1986). The psychology of the Chinese people. Hong Kong: Oxford University Press.

Brown, P., \& Levinson, S. (1987). Politeness: Some universals in language usage. Cambridge, England: Cambridge University Press.

Daniels, B. C. (1995). Puritans at play. New York: St. Martin's Press.

DePaulo, B., \& Kashy, D. (1998). Everyday lies in close and casual relationships. Journal of Personality and Social Psychology, 74, 63-79.

Earley, P. C. (1997). Face, harmony and social structure: An analysis of organizational behavior across cultures. New York: Oxford University Press.

Farh, J.-L., Tsui, A., Xin, K., \& Cheng, B.-S. (1998). The influence of relational demography and guanxi: The Chinese case. Organizational Science, 9, 471-488.

Furnham, A. (1990). A content, correlational, and factor analytic study of seven questionnaire measures of the Protestant work ethic. Human Relations 43, 383-399.

Goffman, E. (1967). Interaction ritual: Essays in face-to-face behavior. New York: Pantheon Books.

Grice, H. P. (1968). Utterer's meaning, sentence-meaning and word meaning. Foundations of Language, 4, 225-242.

Hall, E. (1983). The dance of life. New York: Anchor Press.

Holtgraves, T. (1997). Styles of language use: Individual and cultural variability in conversational indirectness. Journal of Personality and Social Psychology, 73, 624-637.

Hong, Y., Chiu, C., \& Kung, T. (1997). Bringing culture out in front: Effects of cultural meaning system activation on social cognition. In K. Leung, Y. Kashima, U. Kim, \& S. Yamaguchi (Eds.), Progress in Asian social psychology (pp. 135-146). New York: Wiley.

Hong, Y., Morris, M., Chiu, C., \& Benet-Martínez, V. (2000). Multicultural minds: A dynamic constructivist approach to culture and cognition. American Psychologist, 55, 709-720.

Hui, C., \& Luk, C. (1997). Industrial/organizational psychology. In J. Berry, M. Segall, \& C. Kagitcibasi (Eds.), Handbook of cross-cultural psychology (pp. 371-412). Needham Heights, MA: Allyn \& Bacon.

Kool, R., \& Saksena, N. K. (1988). Leadership styles and its effectiveness among Indian executives. Indian Journal of Applied Psychology, 26, $9-15$.

LaFromboise, T., Coleman, H., \& Gerton, J. (1993). Psychological impact of biculturalism: Evidence and theory. Psychological Bulletin, 114, $395-412$.

Lee, F. (1993). Being polite and keeping MUM: How bad news is communicated in organizational hierarchies. Journal of Applied Social Psychology, 23, 1124-1149.

Lee, F. (1999). Verbal strategies for seeking help in organizations. Journal of Applied Social Psychology, 29, 1472-1496.

Lenski, G. (1963). The religious factor: A sociological study of religious impact on politics, economics and family life. Garden City, NY: Anchor Books.

Markus, H., \& Kitayama, S. (1991). Culture and the self: Implications for cognition, emotion, and motivation. Psychological Review, 98, 224253.

Phinney, J., \& Devich-Navarro, M. (1997). Variations in bicultural identification among African American and Mexican American adolescents. Journal of Research on Adolescence, 7, 3-32.

Sanchez-Burks, J. (2002). Protestant relational ideology and (in)attention to relational cues in work settings. Journal of Personality and Social Psychology, 83, 919-929.

Sanchez-Burks, J., Nisbett, R. E., \& Ybarra, O. (2000). Cultural styles, 
relational schemas and prejudice against outgroups. Journal of Personality and Social Psychology, 79, 174-189.

Singelis, T., Triandis, H., Bhawuk, D., \& Gelfand, M. (1995). Horizontal and vertical dimensions of individualism and collectivism: A theoretical and measurement refinement. Cross-Cultural Research: The Journal of Comparative Social Science, 29, 240-275.

Ting-Toomey, S., Gao, G., Trubisky, P., Yang, Z., Kim, H. S., Lin, S. -L., \& Nishida, T. (1991). Culture, face maintenance, and styles of handling interpersonal conflict: A study in five cultures. International Journal of Conflict Resolution, 2, 275-296.

Trafimow, D., Triandis, H., \& Goto, S. (1991). Some tests of the distinction between the private self and collective self. Journal of Personality and Social Psychology, 60, 649-655.

Triandis, H. C., Dunnette, M. D., \& Hough, L. M. (1994). Handbook of industrial and organizational psychology. New York: Consulting Psychologists Press.

Triandis, H. C., Marin, G., Lisansky, J., \& Betancourt, H. (1984). Simpatía as a cultural script of Hispanics. Journal of Personality and Social Psychology, 47, 1363-1375.

Weber, M. (1930). Protestant ethic \& the spirit of capitalism. New York: Routledge. (Originally published 1904, Winchester, MA: Allen \& Unwin).

Weber, M. (1947). The theory of social and economic organization (T. Parsons, Trans.). New York: Free Press.

Received October 11, 2002

Revision received December 23, 2002

Accepted January 16, 2003

\title{
Call for Nominations
}

The Publications and Communications (P\&C) Board has opened nominations for the editorships of Comparative Psychology, Experimental and Clinical Psychopharmacology, Journal of Abnormal Psychology, Journal of Counseling Psychology, and JEP: Human Perception and Performance for the years 2006-2011. Meredith J. West, PhD, Warren K. Bickel, PhD, Timothy B. Baker, PhD, JoIda C. Hansen, $\mathrm{PhD}$, and David A. Rosenbaum, $\mathrm{PhD}$, respectively, are the incumbent editors.

Candidates should be members of APA and should be available to start receiving manuscripts in early 2005 to prepare for issues published in 2006. Please note that the P\&C Board encourages participation by members of underrepresented groups in the publication process and would particularly welcome such nominees. Self-nominations also are encouraged.

Search chairs have been appointed as follows:

- Comparative Psychology, Joseph J. Campos, PhD

- Experimental and Clinical Psychopharmacology, Linda P. Spear, $\mathrm{PhD}$

- Journal of Abnormal Psychology, Mark Appelbaum, PhD, and David C. Funder, $\mathrm{PhD}$

- Journal of Counseling Psychology, Susan H. McDaniel, PhD, and William C. Howell, PhD

- JEP: Human Perception and Performance, Randi C. Martin, PhD

To nominate candidates, prepare a statement of one page or less in support of each candidate. Address all nominations to the appropriate search committee at the following address:

\author{
Karen Sellman, P\&C Board Search Liaison \\ Room 2004 \\ American Psychological Association \\ 750 First Street, NE \\ Washington, DC 20002-4242
}

The first review of nominations will begin December 8, 2003. The deadline for accepting nominations is December 15, 2003. 